\title{
LONGSHORE CURRENT PROFILES AND LATERAL MIXING ACROSS THE SURF ZONE OF A BARRED NEARSHORE
}

\author{
BRIAN GREENWOOD ${ }^{1,2}$ and DOUGLAS J. SHERMAN ${ }^{1, a}$ \\ 'Department of Geography and ${ }^{2}$ Department of Geology, Scarborough Campus, Univer- \\ sity of Toronto, Scarborough, Ont. M1C 1A4, Canada
}

(Received October 5, 1984; revised and accepted December 12, 1985)

\section{ABSTRACT}

Greenwood, B. and Sherman, D.J., 1986. Longshore current profiles and lateral mixing across the surf zone of a barred nearshore. Coastal Eng., 10: 149-168.

Longshore currents were measured during a storm in a barred surf zone in the Great Lakes. Mean beach slope was 0.015 , with three bars ranging up to $0.5 \mathrm{~m}$ in height. Comparisons with theoretical predictions revealed the effects of the bars on the horizontal structure of these currents and the degree of lateral mixing: (1) perturbations in currents are localized spatially but increase with bar relief; (2) currents are lower and higher respectively in the outer and inner surf zone than expected for a plane beach. The predictions of Longuet-Higgins (1972) provide a reasonable approximation where relief is low; $(3)$ in the inner surf zone a plane beach solution suggests bars increase lateral mixing $(P \simeq 1.0)$ by increasing the velocity gradients; $(4)$ the barred slope model of Ebersole and Dalrymple (1981) most closely resembles the prototype; (5) use of planar beach equivalents for $P$ or $N$ in models for barred beaches, results in under-prediction of the appropriate eddy viscosity.

\section{INTRODUCTION}

An understanding of the complex fluid behaviour within active surf zones is of considerable importance to scientists and engineers who deal with the coastal zone. However, present knowledge of these hydrodynamics is limited by a lack of a complete theory for breaking gravity waves (Longuet-Higgins, 1981) and of field data accurately describing flows in natural surf zones. Information describing shore-parallel flows (longshore currents) is of particular interest because they are the primary advecting agents for both fluid and sediment alongshore. Modern theory for the prediction of longshore currents followed the introduction of the concept of radiation stress by Longuet-Higgins and Stewart $(1962,1963,1964)$ and the basic solutions for currents induced by waves breaking at an angle to the shoreline were proposed by Bowen (1969), and Longuet-Higgins (1970a, b).

a Currently Assistant Professor, Department of Geography, University of Southern California, Los Angeles, CA 90007, U.S.A. 
Fundamental to both derivations was the incorporation of a parameter describing the horizontal diffusion of momentum across the surf zone and its effect on the spatial variability of nearshore currents. This lateral mixing is, therefore, a key variable in any prediction of horizontal velocity profiles and potential sediment transport by shore parallel flows.

This paper examines the basic form proposed for the mixing parameter and describes a field experiment designed specifically to: (a) measure the horizontal velocity structure of shore-parallel flow in a surf zone characterized by a number of nearshore bars; (b) compare the prototype results to theoretical predictions; (c) determine the effect of non-planar bathymetry on the lateral mixing and eddy viscosity estimates.

\section{REYNOLDS STRESSES AND EDDY VISCOSITY}

Longuet-Higgins $(1970 a, b)$ suggested that when waves break at an oblique angle to a planar beach, the flux toward the shoreline of the alongshore flux of momentum provides the lateral thrust necessary to generate shoreparallel flows. This quantity is obtained from the tensor transformation of the two-dimensional stress system:

$S=\left[\begin{array}{ll}S_{x x} & S_{x y} \\ S_{y x} & S_{y y}\end{array}\right]=E\left[\begin{array}{lr}\frac{3}{2} \cos ^{2} \theta & \cos \theta \sin \theta \\ \cos \theta \sin \theta & \frac{1}{2} \sin ^{2} \theta\end{array}\right]$

where $S=$ the total radiation stress, $S_{x x}=$ the onshore component of the onshore radiation stress, $S_{y y}=$ the alongshore component of the alongshore radiation stress, $S_{x y}=$ the onshore component of the alongshore radiation stress, $S_{y x}=$ the alongshore component of the onshore radiation stress, $E=$ wave energy density, $\theta=$ the angle of wave approach and $x$ and $y$ are the onshore and alongshore directions respectively.

The wave energy, as used in eqn. (1), may be conveniently expressed using linear shallow water theory as a function of the water particle velocity under the waves:

$u_{\mathrm{m}}=\left[\frac{2 E_{\mathrm{b}}}{\rho h_{\mathrm{b}}}\right]^{1 / 2}=\left[\frac{\frac{1}{4} g H_{\mathrm{b}}{ }^{2}}{h_{\mathrm{b}}}\right]^{1 / 2}$

where $u_{\mathrm{m}}=$ the maximum orbital velocity, $h=$ the water depth, $H=$ wave height, $\rho=$ mass density, $g=$ gravitational constant, and the subscript $b$ refers to the conditions at wave breaking. From solitary wave theory (Munk, 1949), $H_{\mathrm{b}}$ may be found as a constant function of $h_{\mathrm{b}}$; that is, $H_{\mathrm{b}} / h_{\mathrm{b}}=$ 0.8261 (Longuet-Higgins, 1974) and using wave amplitude $(0.5 H)$ this breaking criterion $(\gamma)$ becomes $\simeq 0.4$.

Longuet-Higgins $(1970 a)$ uses the maximum horizontal orbital velocity to develop his expression for the local wave stress:

$S_{x y}=\frac{5}{4} \rho u_{\mathrm{m}}^{2}(s \sin \theta \cos \theta)$ 
where $s$ is the nearshore slope ( $s \equiv-\mathrm{d} h / \mathrm{d} x$ and $x$ is the offshore distance). This wave thrust is the driving force generating the longshore current, which at equilibrium is balanced by bottom boundary friction if lateral friction is ignored. Assuming a linear decay of breaker height across the surf zone (proportional to depth) then a linear decay of current velocity would also occur, with maximum velocities at the initial break point and no current outside the surf zone. However, as was pointed out by Longuet-Higgins, both experiment and observation have revealed maximum velocities displaced landward of the break point. While part of this could be attributed to shifting of the breaker line (Thornton, 1978), of greater importance are the viscous forces acting normal to the shoreline. Under breaking waves these forces are anisotropic and involve an advection of momentum that modifies the otherwise linear decay of velocities. The magnitude of these Reynolds stresses depend upon the eddy viscosity:

$\mu_{\mathrm{e}}=\rho l^{2}(\partial v / \partial x)$

where $\mu_{\mathrm{e}}=$ the eddy viscosity, $v$ is the longshore current velocity and $l=$ a mixing length.

A number of formulations are available for estimating the horizontal eddy viscosity in the surf zone (Longuet-Higgins, 1970a, b; Battjes, 1975; Madsen et al., 1978) although all are of the same general form. Because $\mu_{\mathrm{e}}$ has the dimensions of $\rho l U$, Longuet-Higgins $(1970 \mathrm{~b}, 1972)$ suggests that a suitable approximation would be the relationship:

$\mu_{\mathrm{e}}=N \rho|x|(g h)^{1 / 2}$

Here, $N$ is a constant composed of three components: $\gamma$, the solitary wave theory breaking criterion [extracted from $u_{\mathrm{m}}=\gamma(g h)^{1 / 2}$ ]; a constant, 0.4, the function of the distance of the centre of the eddies from the boundary, as suggested by Prandtl (1952) and extracted from the mixing length $l=$ $0.4|x|$ ); and the ratio of the turbulent velocities to the mean velocities. Longuet-Higgins suggested that the ratio of turbulent to mean velocities should be about 0.1 for normal turbulence, and therefore a typical approximation of $N$ is 0.016 . He defines the constant $N$ in terms of a dimensionless mixing parameter $P$, which represents the relative importance of horizontal mixing to bed friction and where the mixing length was assumed to be proportional to the distance offshore:

$P \equiv \frac{\pi}{2} \frac{s N}{\gamma C}$

where $C=$ a drag coefficient. In contrast, Battjes' (1975) formulation assumes that the appropriate scale of the turbulent eddies would be that of the water depth at the breaker line. 
By general consensus Longuet-Higgins' formulation for the generation and spatial distribution of shore-parallel flows due to obliquely breaking waves is sound in approach (Ostendorf and Madsen, 1979; Basco, 1982). Accordingly (Longuet-Higgins, 1972), the mean depth-integrated, longshore current at the breaker line without lateral mixing is given by:

$v_{\mathrm{b}}=\frac{5 \pi}{8} \frac{\gamma}{C} s\left(g h_{\mathrm{b}}\right)^{1 / 2} \sin \theta \cos \theta$

with $v$ decreasing linearly to zero at the shoreline, and no current outside the surf zone (Fig. 1a). By estimating potential lateral mixing effects, Longuet-Higgins also provides a range of possible solutions for a dimensionless velocity distribution across the surf zone based upon:

$V= \begin{cases}A X+B_{1} X^{p_{1}}, & 0<X<l \\ B_{2} X^{p_{2}}, & l<X<\infty\end{cases}$

Here, $V$ is a dimensionless current velocity $\left(v / v_{\mathrm{b}}\right), X$ is a dimensionless offshore distance $\left(|x| / x_{\mathrm{b}}\right)$. The constants, $A, B_{1}, B_{2}, p_{1}$ and $p_{2}$ depend upon $P$, as demonstrated by Longuet-Higgins (1972) in his derivation. The effects of variability in $P$ are illustrated in Fig. 1a. Low values for the mixing parameter give steep velocity gradients and a rapid reduction in flow outside the breaker line. In contrast, large mixing values produce low gradients and shore-parallel flows that extend well outside the surf zone. Based upon observations of dye patch diffusion (Harris et al., 1962; Inman et al., 1971), low values of $P$ have been assumed for the prototype, but there are still relatively few data sets which allow a direct test of the predicted velocity distributions.

A basic assumption of eqn. (7) is that the nearshore slope is planar. In an effort to derive potential solutions for a barred nearshore, Symonds and Huntley (1980) adopted the Longuet-Higgins approach and assumed that the nearshore slope consisted of two discrete planes separated by a sharp discontinuity (Fig. 1b). Ebersole and Dalrymple (1981) used a more realistic bathymetry and a numerical solution for deriving the velocity profile across a nearshore bar (Fig. 1c).

To evaluate these theoretical distributions for longshore currents in the surf zone, an experiment was carried out in a barred nearshore to obtain data describing these flows.

\section{EXPERIMENTAL DESIGN}

Wendake Beach, Ontario, Canada (Fig. 2), was selected for the study site. It is a low-energy, storm-wave dominated coast with a maximum ef- 
fective fetch of $84 \mathrm{~km}$ to the WNW. Short, steep waves, exceeding $2 \mathrm{~m}$ significant height and 5 to $6 \mathrm{~s}$ period, may be generated as cyclonic disturbances move through the region. Shore-parallel flows are to the NE or SW depending on the angle of wave approach, and may change even within a single storm in response to wind shifts in this fetch limited environment.

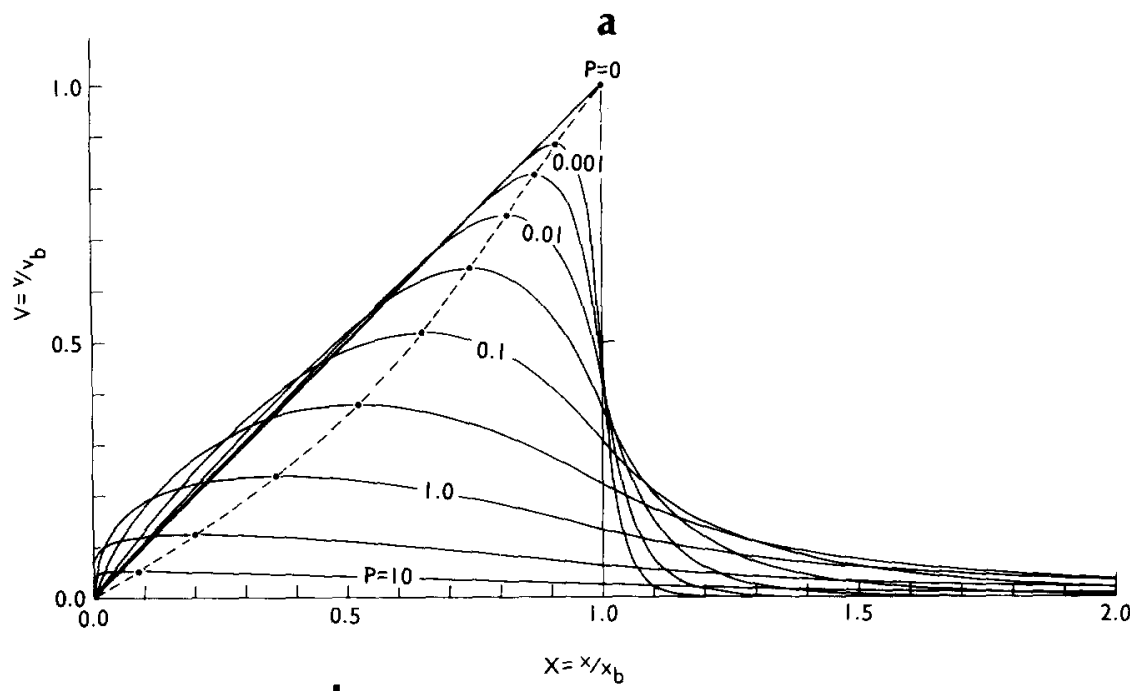

b
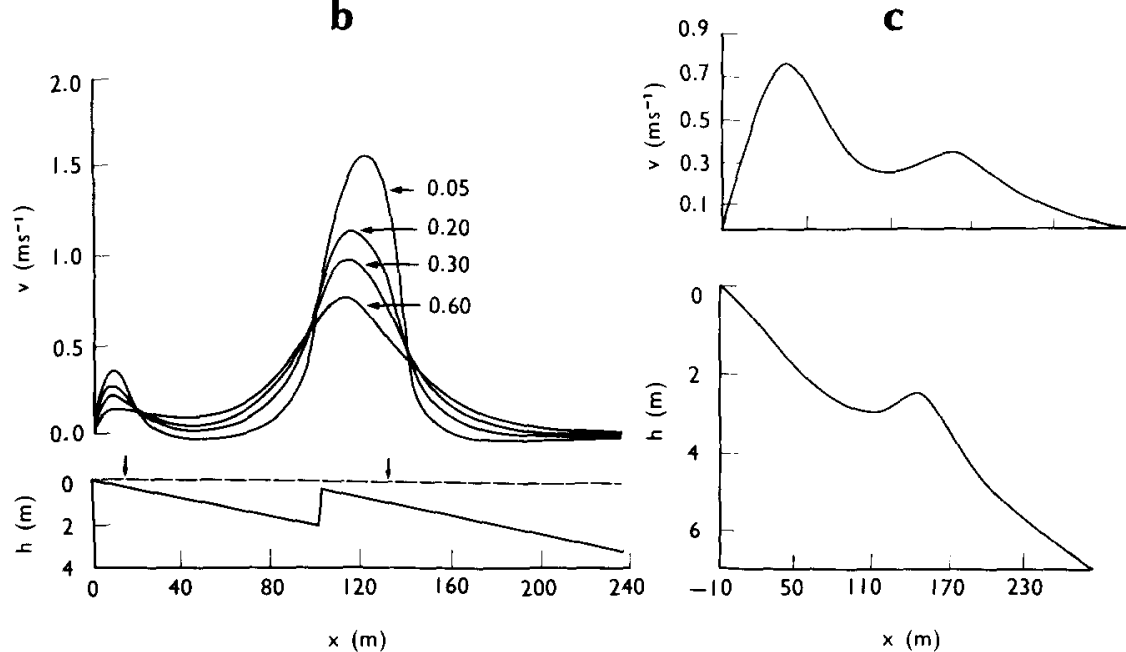

Fig. 1. Theoretical longshore current profiles: (a) dimensionless velocity profiles across a planar surf zone for differing values of the lateral mixing parameter, $P$ (after LonguetHiggins, 1972); (b) velocity and slope profiles across a barred surf zone for differing values of the lateral mixing parameter, $P$ (after Symonds and Huntley, 1980). A $1-\mathrm{m}$ incident wave height and angle of incidence of $35^{\circ}$ was used. The arrows mark the break points; (c) velocity and slope profile across a barred surf zone using a value for $N$ of 0.005 (Ebersole and Dalrymple, 1981). 


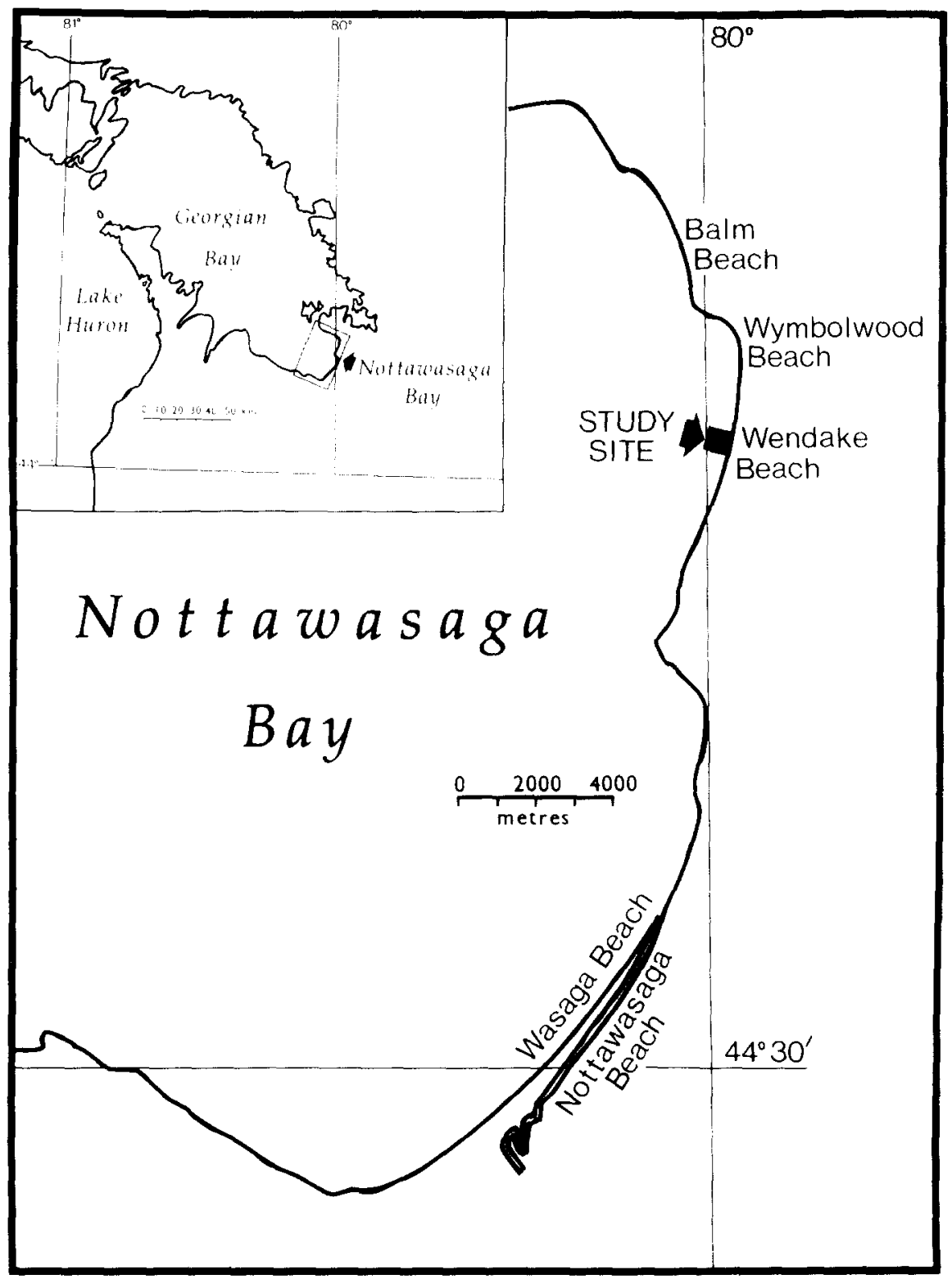

Fig. 2. Location of study site.

Nearshore bathymetry

Beach profile measurements were made using an engineer's level and stadia rod in shallow water and a fathometer in deeper water. Thirteen shorenormal lines, each $525 \mathrm{~m}$ long, were laid out at $30-\mathrm{m}$ intervals and were 
surveyed before and after the experiment. These measurements were important for the determination of beach slope, the identification and description of significant morphological features, the estimation of beach orientation and for the precise locating of the instruments.

The nearshore is characterized by 3 bars of low amplitude on a 0.015 average slope (Fig. 3); the outermost bar is largest and essentially straight with a crest some $110 \mathrm{~m}$ offshore, while the inner bars are sinuous in form. Bars increase in size and spacing lakeward from the shoreline. The surf zone width is clearly constrained by these bars under many conditions but the general slope is so shallow that breaking occurs lakeward of the outermost bar at the peak of storms and is continuous to the swash zone.

\section{Instrumentation}

Wave and current patterns across Wendake Beach were determined using ten, helically wound, continuous resistance wave staffs mounted on galvanized steel supports, and seven, bi-directional, electromagnetic flow meters. A shore-normal array was deployed (Fig. 3) with spacings constrained by the number of flowmeters available and the need to identify the influence of the two outer bars on the flow field. Current meters were oriented underwater to within $1^{\circ}$ using an alignment device consisting of a level bubble

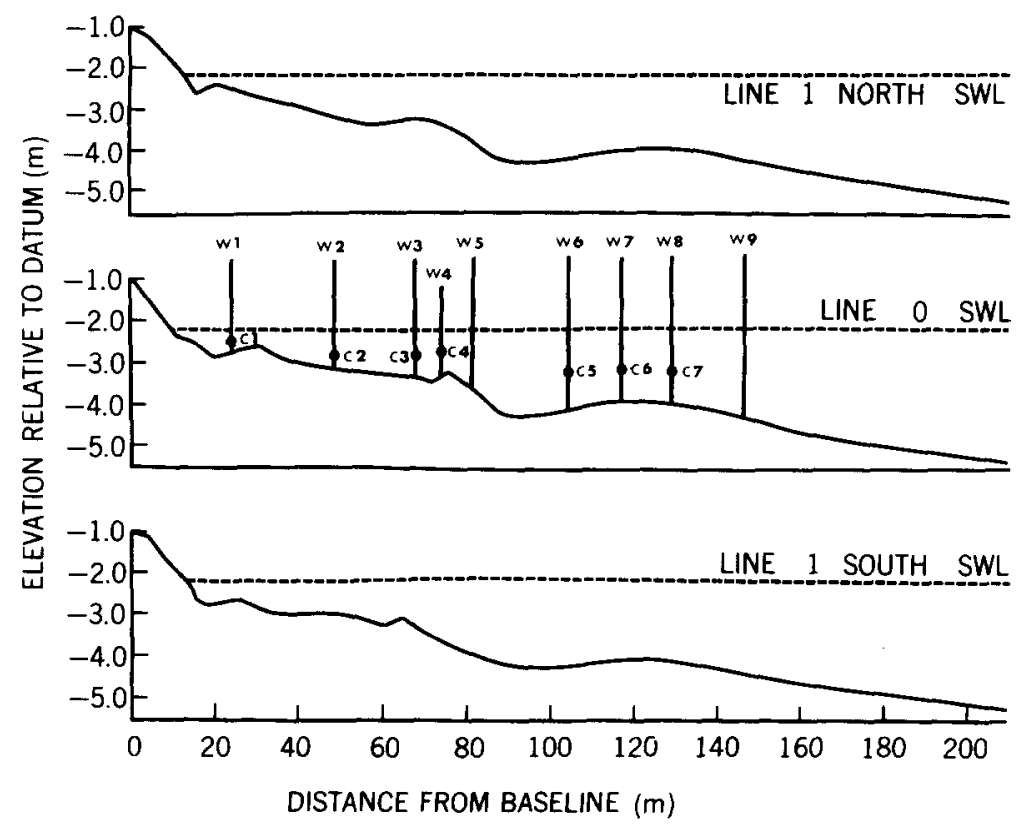

Fig. 3. Nearshore profiles and instrument deployment, Wendake Beach. The three profiles were located $30 \mathrm{~m}$ apart and the zero line was the instrument transect: $c=$ electromagnetic flowmeter, $w=$ wave wire. 
and underwater compass (Sherman, 1983). Wave wire number nine was used for recording the incident wave spectrum considered outside of the surf zone. All instruments were hardwired to shore where a custom-designed interface provided power and signal conditioning. Currents and waves were sampled in a burst mode with a high-speed multiplexer and analogue-todigital converter controlled by a mini-computer with $128 \mathrm{~K}$ bytes of storage and real time clock control (more detail is given in Greenwood, 1982). Record lengths were 9 minutes in most instances and the sampling rate was $2 \mathrm{~Hz}$. It was anticipated that this would give a reasonable value for a mean flow, which could be assumed to be stationary over this interval.

The basic dataset used in the following analysis comprises nine discrete spatial series of current and wave records taken through the period of a single storm May 31 to June 1, 1980. Full details of the general temporal and spatial series are available in Greenwood and Sherman $(1983,1984)$. Waves, initially generated by wind out of the westerly quadrant, induced mean northerly flows in the nearshore up to $0.4 \mathrm{~m} \mathrm{~s}^{-1}$; but a switch in wind direction to the north caused a rapid change in the direction of wave approach and a reversal of the direction of shore-parallel flow.

\section{MODEL REQUIREMENTS}

To obtain the required parameters and satisfy the underlying assumptions of the theory of Longuet-Higgins, it was necessary to simplify the prototype data. Values of incident wave amplitude and angle, mean beach slope and bed friction were required.

\section{Incident wave amplitude and angle}

The spectral peak of the water-surface elevation record, as measured at wave wire nine, was used to estimate the root-mean-square wave amplitude (see Sherman, 1983; Sherman and Greenwood, 1986 for complete details). This record was selected as being representative of wave conditions at the outer edge of the surf zone. Measurement of wave angle is especially difficult within the nearshore zone as it is constrained not only by environmental complexity, but also by the accuracy of instrument orientation. In this study, flowmeter and wave staff records were used to determine the orbital velocities due to the incident wave field; separating these from other influences on the water motion, a direction of wave approach is computed. A procedure of weighting based upon the coherence between the horizontal current components $(u$ and $v$ ), measured by a flow meter, and the surface elevation, measured by the wave staff, for each frequency band under the incident spectral peak is carried out in a number of steps (Sherman and Greenwood, 1986):

(1) The width of the incident spectral peak was defined following Pawka et al. (1976). 
(2) Using the frequency bands under this peak, the orbital velocity vector, relative to shore-normal, was obtained for each bandwidth in the current records. The $u$ and $v$ components were weighted by the coherence squared between the velocity component and the surface elevation record.

(3) Each vector angle was then weighted according to the energy content of that same frequency.

(4) A simple summation of the weighted angles gave the estimated mean wave angle.

\section{Beach slope and surf zone width}

Longuet-Higgins (1972) and most subsequent workers have assumed a planar beach slope as a practical nearshore approximation. This is clearly not appropriate at Wendake Beach where the mean slope will change as the surf zone width changes. To provide a linear solution, the surf zone widths were determined using a least squares approximation for the nearshore slope which explained $95 \%$ of the variance in the barred profile; using the equation for this line ( $h=0.013 x+0.4$, where $x=$ distance from the shoreline), wave amplitude and the breaking criterion, the width of the surf zone $\left(x_{b}\right)$ at any time can be defined. The mean value for the slopes of each surf zone width was 0.015 .

\section{Bed friction}

This is a difficult parameterization and open to considerable debate. Longuet-Higgins $(1970 a, b)$ in his original formulation examined a number of alternate suggestions and proposed a value for a Chezy-type friction coefficient of 0.01 . Sonu (1972) suggested a value of 0.014 for his numerical solution to a nearshore circulation pattern and Komar (1975) suggested, for field conditions, a drag coefficient of $0.017-0.018$. It is known that the surf zone friction factor will vary according to the degree of interaction between waves and currents (Jonsson et al., 1974; Grant and Madsen, 1979; Ostendorf and Madsen, 1979), the concentration of suspended and bed load (Smith and McLean, 1977; Grant and Madsen, 1982) and the bed configuration (Smith and McLean, 1977; Jonsson, 1980; Sherman and Greenwood, 1984). As a first approximation, an estimate for bed friction at Wendake Beach was derived using an expression based upon the work of Nikuradse $(1932,1933)$, which gives a Darcy-Weisbach type $f$, assuming a fully turbulent flow, smooth planar boundary, and roughness length represented by the grain roughness $\left(k_{\mathrm{s}}\right)$ :

$$
f=\frac{1}{4\left[0.57-\log _{10}\left(k_{\mathrm{s}} / 4 h\right)\right]^{2}}
$$


where $k_{\mathrm{s}} \simeq 2 D_{50}$ and $D_{50}=$ mean grain size. Grain size variation across the surf zone was measured and an areally-weighted mean grain diameter of $0.21 \mathrm{~mm}$ obtained. An $f$ value of 0.015 was obtained from this procedure. Because of the assumed plane bed configuration, this value should be close to a minimum condition for $f$. Subsequent friction estimates for the total boundary roughness, based upon vertical velocity profiles in the outer surf zone at Wendake Beach, gave values ranging from 0.015 to 0.041 (Sherman and Greenwood, 1984).

\section{PROTOTYPE DIMENSIONLESS VELOCITY PROFILES}

To obtain the dimensionless velocity profiles, $V$ and $X$ must be determined using estimates of wave height, angle of wave approach and the width of the surf zone. Table 1 summarizes the data used in these calculations.

\section{TABLE 1}

Surf zone characteristics used for the derivation of dimensionless velocity profiles: $a_{\mathrm{rms}}=$ root-mean-square wave amplitude, $\theta=$ angle of wave approach, $x_{\mathrm{b}}=$ width of the surf zone.

\begin{tabular}{llrl}
\hline $\begin{array}{l}\text { Time } \\
(\mathrm{h})\end{array}$ & $\begin{array}{l}a_{\text {rms }} \\
(\mathrm{m})\end{array}$ & \multicolumn{1}{c}{$\begin{array}{l}\theta \\
\left({ }^{\circ}\right)\end{array}$} & \multicolumn{1}{c}{$\begin{array}{l}x_{\mathbf{b}} \\
(\mathrm{m})\end{array}$} \\
\hline $15: 00$ & 0.64 & 10.4 & 96 \\
$16: 15$ & 0.76 & 10.3 & 118 \\
$17: 15$ & 0.91 & 10.2 & 149 \\
$18: 30$ & 0.83 & 9.2 & 132 \\
$20: 00$ & 0.77 & 7.4 & 121 \\
$22: 00$ & 1.32 & 7.9 & 229 \\
$00: 25$ & 1.23 & 5.2 & 212 \\
$03: 20$ & 0.90 & 10.0 & 146 \\
$06: 20$ & 0.73 & 6.9 & 113 \\
\hline
\end{tabular}

Figure 4 illustrates the dimensionless velocity profiles during conditions of a well-developed longshore current at Wendake Beach. A number of characteristic features of the flow field are evident:

(a) There is a large spatial variability in the shore-parallei flows. At $1715 \mathrm{~h}$, for example, the velocity on the second bar crest, approximately halfway across the surf zone, was $0.10 \mathrm{~m} \mathrm{~s}^{-1}$; just landward of the bar it was $0.01 \mathrm{~m} \mathrm{~s}^{-1}$ and the peak velocity in the inner surf zone was $0.26 \mathrm{~m}$ $\mathrm{s}^{-1}$ (Fig. 4a). At the height of the storm, $2200 \mathrm{~h}$ (Fig. 4d), the velocities at the same topographic locations were $0.20 \mathrm{~m} \mathrm{~s}^{-1}, 0.11 \mathrm{~m} \mathrm{~s}^{-1}$ and $0.40 \mathrm{~m} \mathrm{~s}^{-1}$ respectively. The latter was the maximum mean longshore current velocity recorded during the experiment. These results contrast markedly with the spatial uniformity suggested by Allender and Ditmars (1981) for a barred nearshore in Lake Michigan. 
(b) Two distinct compartments of shore-parallel flow are delineated by the bar locations and have similar velocity distributions. However, the overall maximum velocity is consistently present in the inner part of the surf zone. This is similar to the pattern suggested by the data of Teleki et al. (1976) for the landward bars of a four-bar system.

(c) In all cases the highest current velocities in each compartment occur landward of the bar crests. However with one exception (Fig. 4e), the shore-parallel components of flow are also smallest immediately landward of the crests. This pattern is found on both the outer and middle bar systems. A lack of instrumentation precludes detection of such a pattern over the inner bar.

It is clear that, even with the relatively low relief in this nearshore zone, the bar topography strongly influences the processes generating shoreparallel flows. On planar beaches, a linear decay in the dissipation of energy landward of the breaker line is predicted by theory. However, with irregular bathymetry, variations in dissipation rates occur as a response to changes in the topographic gradients. For example, increased breaking over the bar crests results in local increases in the momentum flux gradient and higher current speeds at these locations; such a pattern was also found during field experiments by both Allender et al. (1979) and Symonds and Huntley (1980). Furthermore, the presence of deeper water immediately landward of bar crests rapidly reduces wave breaking and thus the stress gradient. This change, coupled with the increased mass of water in the trough, is the most likely cause of the reduction in velocities here. This bar-induced reduction in flow appears to be restricted to a narrow area on the upper landward slope of the bars. Landward of this, a normal pattern of dissipation of wave energy by breaking resumes, and the observed profiles in the inner surf zone appear similar to those predicted by Longuet-Higgins for a plane beach. Thus the bars seem to cause only a localized perturbation in the velocity profiles.

At three times the intriguing case of flow reversals in the surf zone appeared (Fig. 5). At 05:31:15:00, wave activity was still low and breaking was not occurring on the outermost bar: in this case (Fig. 5a) the reversals appear to represent the superimposition of the stormwave field on a preexisting coastal boundary flow. Mean velocities at this time were low (a maximum of $0.09 \mathrm{~m} \mathrm{~s}^{-1}$ in the inner surf zone) and breaking was occurring at the foot of the lakeward slope of the second bar. However, at 06:01:00: 25 and 06:01:3:20 the flow reversals can clearly be related to a change in the direction of wave approach and the superimposition of one wave field on another. A shift in wind direction from westerly to northwesterly occurred around 05:31:22:30, approximately $1.5 \mathrm{~h}$ before the first flow reversal was documented. By 00:25 h flow over the outer part of the inner surf zone had adjusted to the new wave field and flow was southwesterly. Close to the shore, however, strong currents continued to flow north [recorded by two flowmeters (Fig. 5b) and persisted for at least another two hours (Fig. 5c)]. A similar condition was predicted by Komar (1975), 
160

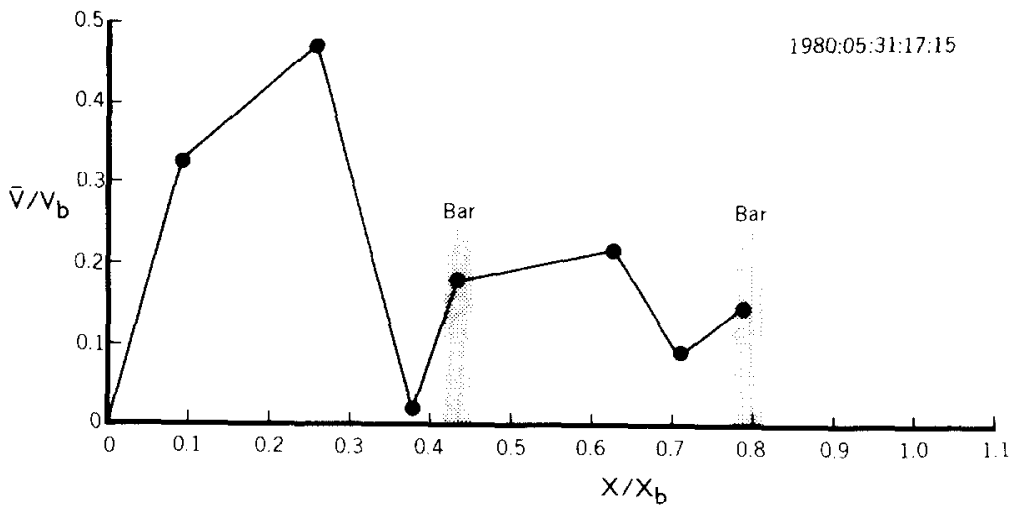

b

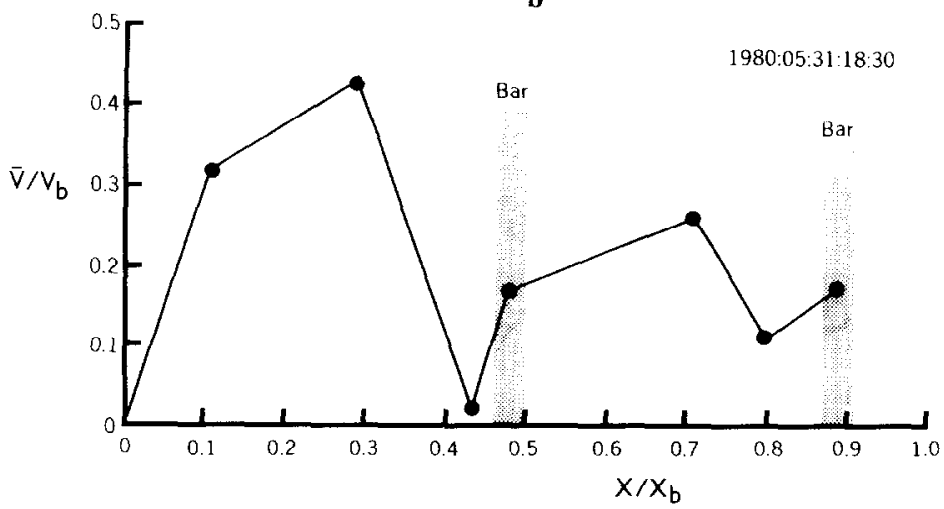

c

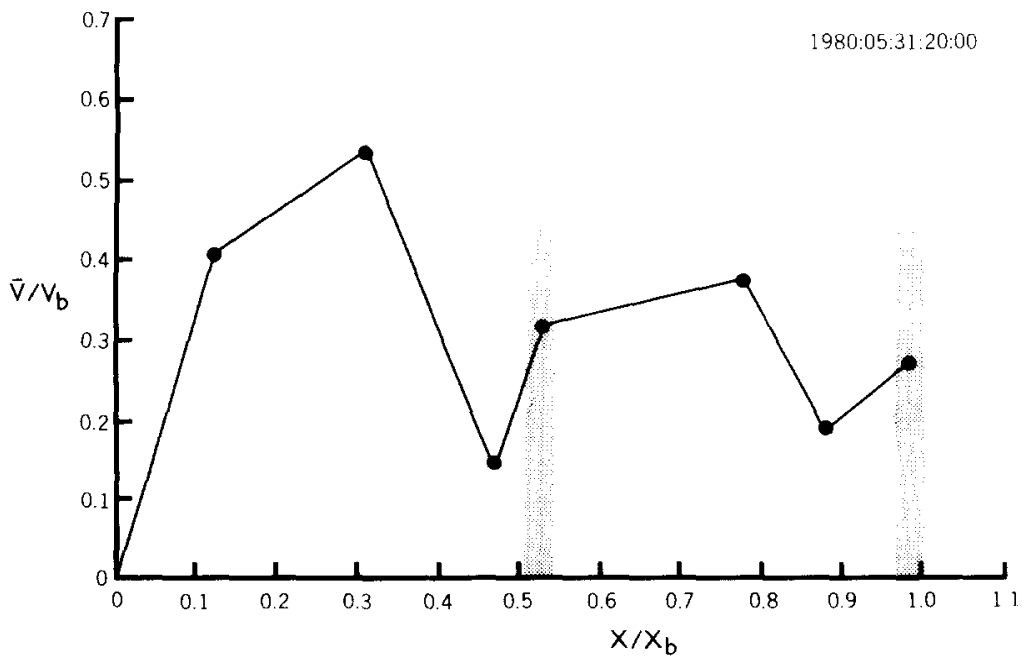



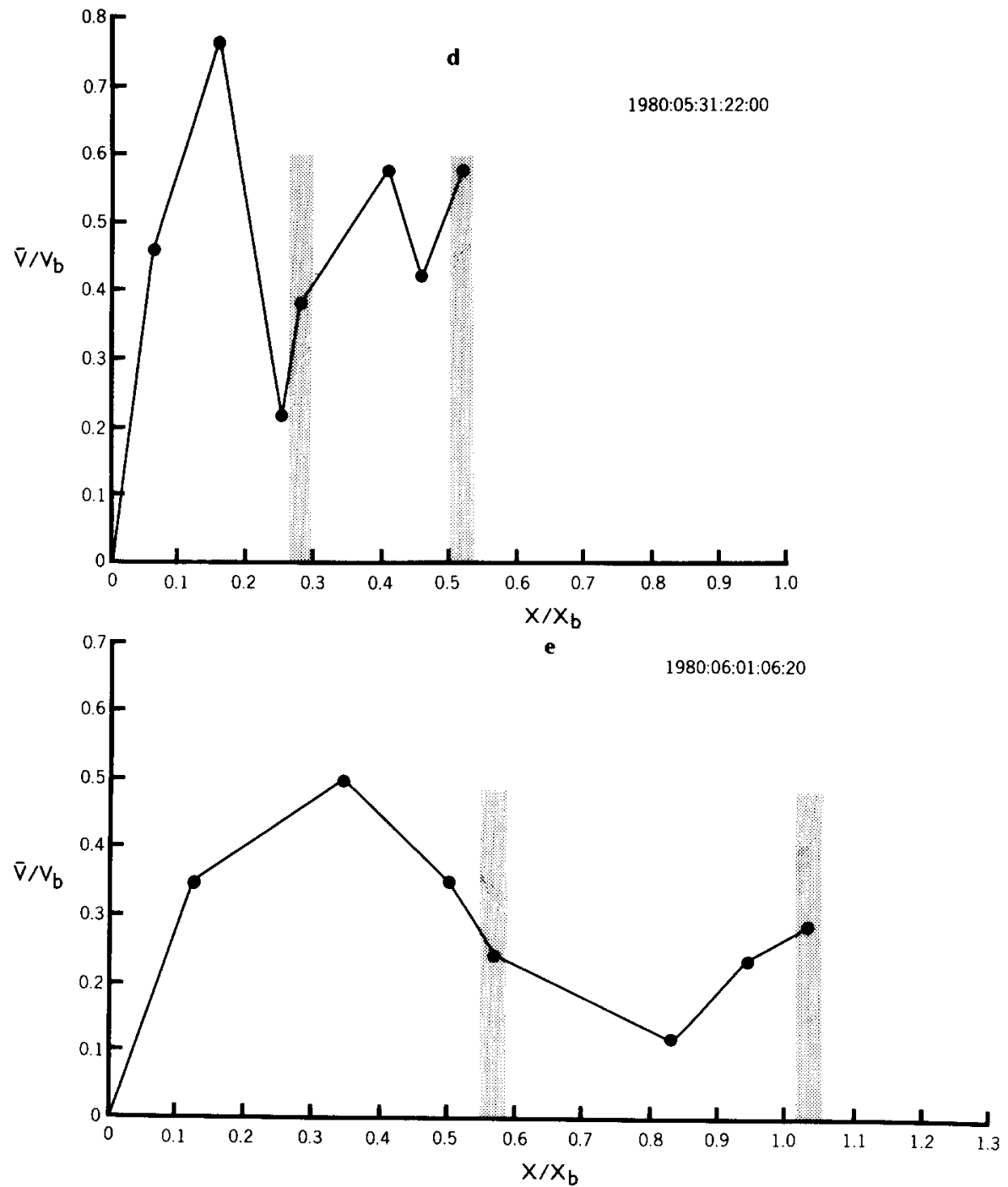

Fig. 4. Dimensionless velocity profiles, 1980:05:31:17:15 to 1980:06:01:06:20. Stipple represents bar crest location.

using a model for longshore flows based on a near balance between forcing due to the oblique angle of wave approach and forcing due to an alongshore pressure gradient. With the instrumentation available here no measurements could be made of any alongshore gradient, and it is clearly possible that such forcing did exist. However, according to Komar, such velocities would be low and the maximum residual velocity would occur near the shoreline. At Wendake Beach, current velocities were close to their storm maxima at the time of these current reversals. Furthermore, the largest velocity was found in the wave-driven flow offshore. 

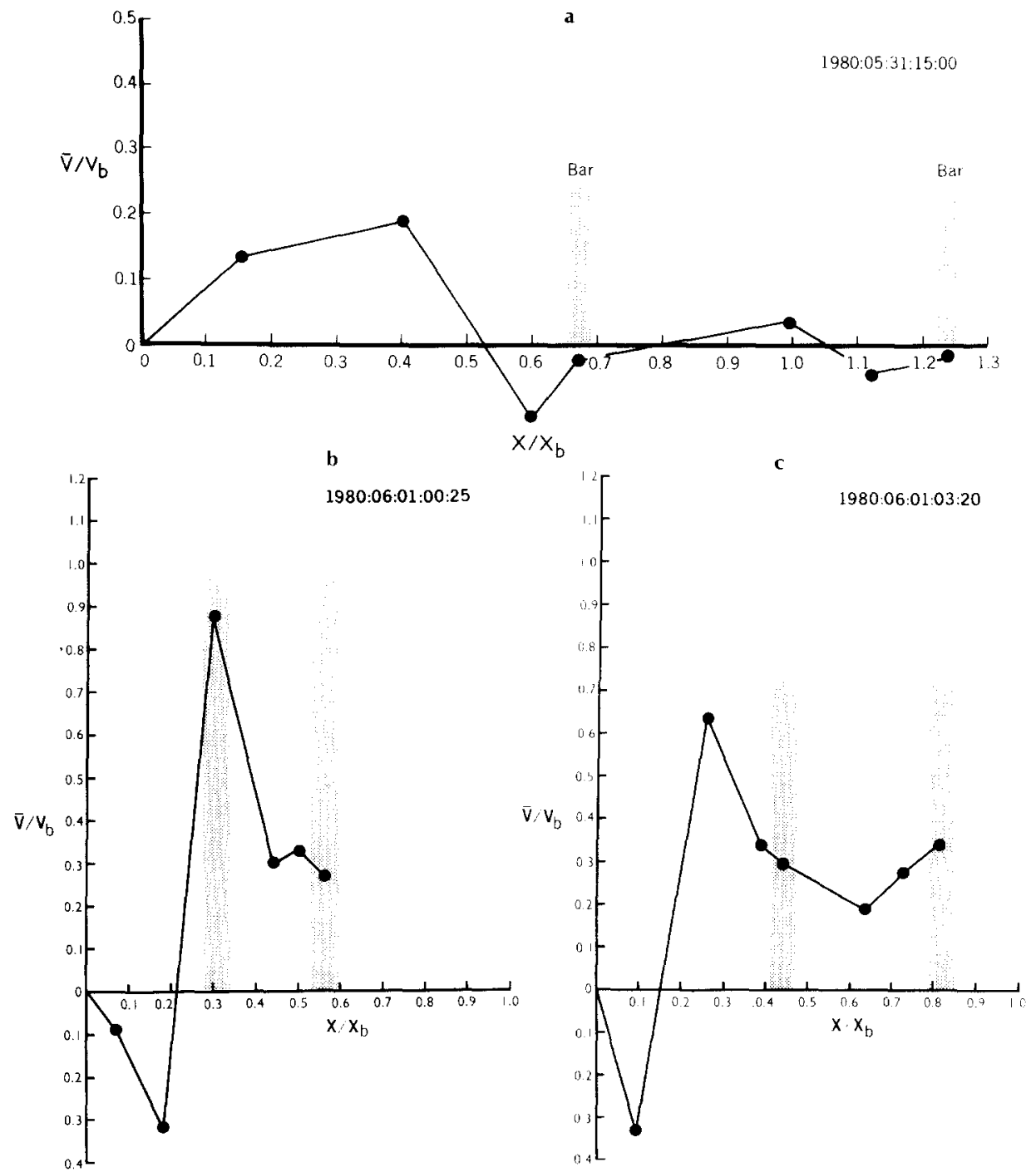

Fig. 5. Dimensionless velocity profiles: (a) 1980:05:31:15:00; (b) 1980:06:01:00:25; (c) 1980:06:01:03:20. Stipple represents bar crest location.

\section{COMPARISON OF MODELS AND PROTOTYPE}

A direct comparison between the prototype data and the planar beach slope model of Longuet-Higgins $(1970 \mathrm{a}, \mathrm{b})$ reveals the perturbations in the velocity distributions induced by the nearshore bars. By averaging the dimensionless velocities at each location across the surf zone from each sampling period, an average dimensionless velocity profile was obtained. Figure $6 \mathrm{a}$ illustrates this together with the theoretical curves for varying degrees of lateral mixing. The general shape of the prototype profile is 
similar to that predicted by theory, but the maximum velocity is skewed landward and the velocity in the outer surf zone is much reduced. This is a result of the outermost trough reducing the radiation stress gradient and increasing the volume of water to be driven. Both of these factors would result in the observed current in the outer trough being smaller than that expected under the planar slope assumption. One of the basic assumptions of the Longuet-Higgins lateral mixing model is that the energy dissipation decreases linearly from a maximum at the breaker line to zero at the water line. This is not the case in a barred nearshore. In the lakeward por-

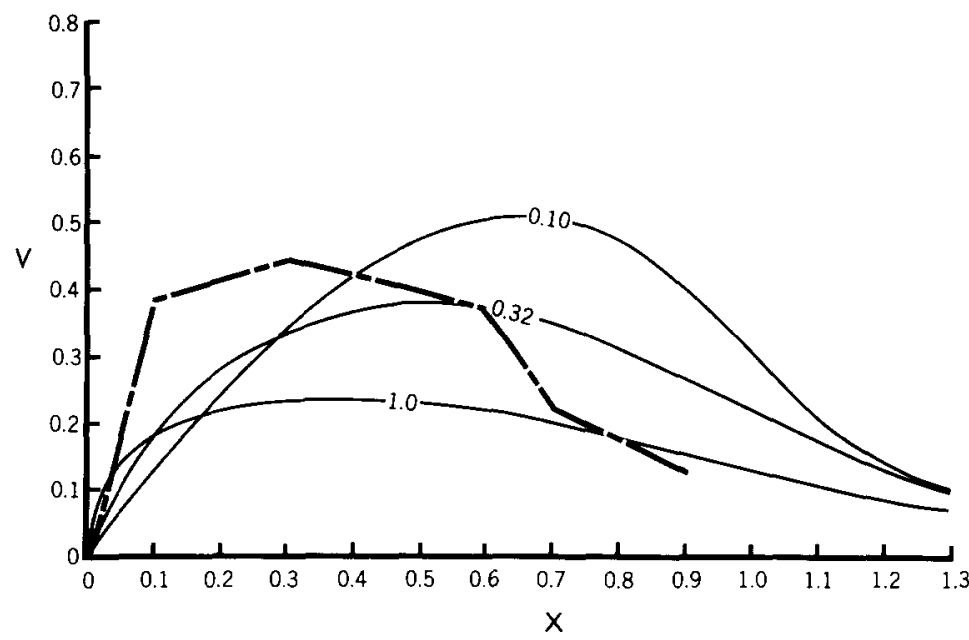

b

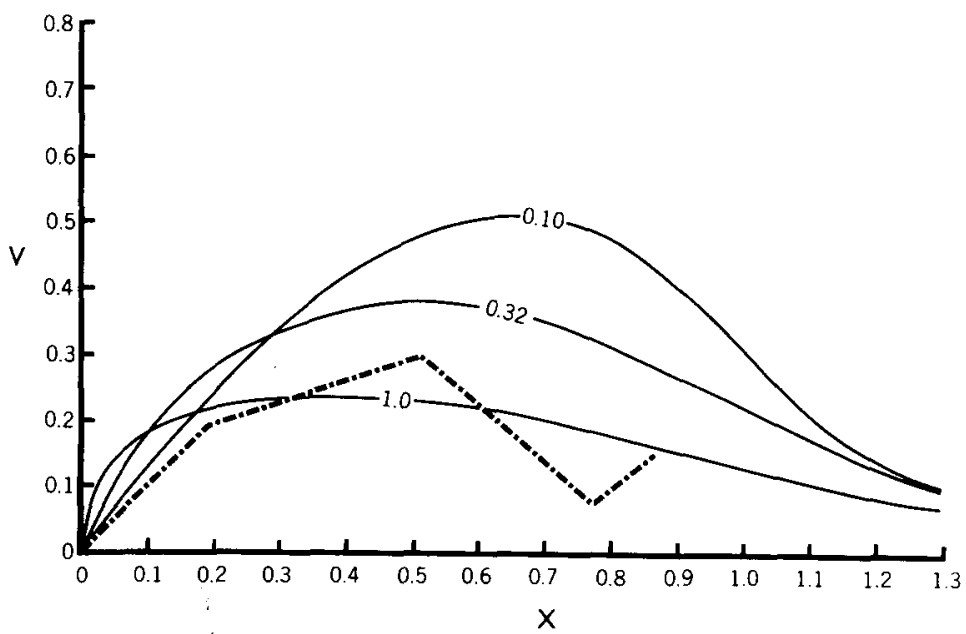

Fig. 6. Average dimensionless velocity profiles measured at Wendake Beach and the theoretical profiles for comparison: (a) for the total width of the barred surf zone; (b) for the inner surf zone. 
tion of the trough, water depth increases rapidly relative to depth over the bar, and thus the rate of energy dissipation is reduced. During the storms at Wendake Beach, waves break continuously across this outer trough, although the intensity of breaking is generally lower than that on the bar crest, and decrease in wave height is minimal. The gradient of radiation stress per unit area of the surf zone is therefore reduced over the outer trough relative to that expected for the planar beach case. The energy that is not dissipated in the outer trough then remains to be dissipated in shallower water. This should cause the stress per unit area of the inner surf zone to be higher than otherwise expected. This effect seems to account for the skewness of the Wendake Beach data (Fig. 6a). However, despite these differences between prototype and theoretical velocity profiles, it is apparent that on a low-relief, barred nearshore the general shape of the spatial distribution of current velocity is still described by eqn. (8).

The individual, dimensionless velocity profiles (Fig. $5 \mathrm{a}, \mathrm{b}, \mathrm{c}$ ) can be compared directly to the single-bar models of Symonds and Huntley (1980) and Ebersole and Dalrymple (1981), shown in Figs. 1b and c, respectively. Although both models exhibit a characteristic bimodal velocity distribution, similar to that of the prototype observed at Wendake Beach, significant differences exist between the three.

Symonds and Huntley (1980) indicate that the maximum velocities occur on the outer bar, with an extremely narrow distribution of flows restricted to the area adjacent to the bar crest. Velocities in the trough were shown to be close to zero with a small secondary peak in velocity near the shoreline. In contrast the Wendake Beach data show two relatively wide peaks in velocity distribution with maximum currents in the inner surf zone. There is, however, some evidence for increased velocities over the lakeward slopes of the two outer bars as suggested by Symonds and Huntley. It would appear that part of the discrepancy between observed and predicted distributions may be directly attributed to the model bathymetry. In the latter, the ratio of water depth over the trough $\left(h_{t}\right)$ to that over the crest $\left(h_{\mathrm{c}}\right)$ would appear to be at least 5:1 (their Fig. 2a). In natural environments this ratio lies in the range 1.16:1 to $1.87: 1$ (Greenwood and Davidson-Arnott, 1975). Therefore, the unrealistically shallow water depth over the bar crest will filter a disproportionately large part of the incident wave energy. Only a minimal driving potential then remains for the rest of the surf zone. This results in the predicted low flows in the inner surf zone.

Ebersole and Dalrymple (1981) use a more realistic bathymetry, with the ratio $h_{\mathrm{t}}: h_{\mathrm{c}}$ approximately $1.5: 1$, and the resulting velocity profile is in better agreement with the prototype. This model shows the highest velocities in the inner system, a relatively wide peak over the bar, and significant velocities in the trough. The observed distributions, however, indicate a greater reduction in velocity immediately landward of the bar crest. It is possible that this too reflects the differences in bathymetry between model and prototype.

The major observed effect of the barred topography at Wendake Beach 
would seem to be the local increases in stress gradients, and therefore velocities, within the surf zone. This must lead to increased mixing at these locations. To provide a first estimate of the extent of this increase, the inner surf zone was treated as if it were a planar nearshore. To solve the necessary equations, the surf zone width was defined using a limiting water depth on the lakeward slope of the middle bar equivalent to the depth over the outer bar crest. This water depth was used to determine the mean slope of the inner surf zone and, in conjunction with the breaking criterion, to solve eqn. (2) for the orbital velocities. Wave angle was provided by data from wave wire four and current meter 4 (see Fig. 4). The friction factor was unchanged. The resulting dimensionless velocity profiles should thus primarily reflect the influence of the second bar.

Figure $6 \mathrm{~b}$ illustrates the comparison between the average, dimensionless velocity profile for the time series (excluding periods of flow reversals) and the theoretical profiles of Longuet-Higgins (1972). These results suggest that an appropriate estimate of the mixing parameter $P$, for this inner surf zone, would be 1.0 . Using this value in eqn. (6) the estimate of $N$ would be 0.19 . Longuet-Higgins (1972) cited values for $P$ of 0.1 and 0.4 for the laboratory data of Galvin and Eagleson (1965), whereas Horikawa and Isobe (1981) found a value of 0.4 , also for laboratory data. Komar (1975) suggested $P$ should be of order 0.1 or less and Kraus and Sasaki (1979) obtained values between 0.05 and 0.1 for prototype data. For the values of $P$ cited by Longuet-Higgins, $N$ lies in the range 0.0024 to 0.0096 . From their limited field data Symonds and Huntley (1980) suggest that even in a barred nearshore $P$ would lie in the same range as that for the planar beach of Longuet-Higgins. Similarly, Ebersole and Dalrymple (1981) used a value for $N(0.005)$ that lies in the middle of the range found by Longuet-Higgins. The results from Wendake Beach suggest that there must be increased mixing within barred surf zones because of the internal velocity gradients, and therefore higher values for these two constants are appropriate.

Substituting the value of $P$, derived from the Wendake experiment, to solve eqn. (5), the eddy viscosity at the outer edge of the inner surf zone becomes $58 \times 10^{3} \mathrm{~kg} \mathrm{~m} \mathrm{~s}^{-1}$. Converting this value to a kinematic eddy viscosity, $v_{\mathrm{e}}=58 \mathrm{~m}^{2} \mathrm{~s}^{-1}$, allows direct comparison with the relationship proposed by Inman et al. (1971): i.e., $\nu_{\mathrm{e}}$ is directly proportional to the quantity $2 a x_{\mathrm{b}} / T$, where $T$ is the wave period. For Wendake Beach the latter relationship predicts $\nu_{\mathrm{e}}$ as equal to $38 \mathrm{~m}^{2} \mathrm{~s}^{-1}$. Thus, the barred beach results are greater than those for a plane beach by about $50 \%$. Furthermore, taking the depth of water at breaking rather than the width of the surf zone as the appropriate control on the mixing length (Battjes, 1975), $\nu_{\mathrm{e}}$ equals $1.3 \mathrm{~m}^{2} \mathrm{~s}^{-1}$. This is approximately three times larger than the model value used by Ebersole and Dalrymple (1981). Thus it appears that the mixing process is enhanced across an irregular nearshore bathymetry and therefore the use of values of $P$ or $N$ obtained from the plane beach configuration is inappropriate for the parameterization of barred beach models. 


\section{CONCLUSIONS}

Based upon the findings of the Wendake Beach experiment, several conclusions may be drawn concerning the effects of bar topography upon longshore current distributions and lateral mixing in the surf zone:

(1) For the whole surf zone, velocities are lower and higher respectively in the outer and inner surf zone than would be expected for a plane beach.

(2) The bar effects are localized spatially, but increase in importance with increasing relative relief of the bars.

(3) With the qualification noted in 1, the Longuet-Higgins (1972) model for predicting the dimensionless surf zone velocity profile does describe the general shape of the velocity profile for a multiple barred beach where relief is low, although quantitatively the fit is poor.

(4) Of the models proposed specifically for barred nearshore slopes, that of Ebersole and Dalrymple (1981) most closely resembles the prototype, at least qualitatively: this appears to result from their more realistic choice of bathymetry.

(5) Dimensionless velocity profiles across the inner surf zone at Wendake Beach, where bar relief is small, can be compared rather successfully with the plane beach model of Longuet-Higgins. For this planar solution, the barred inner surf zone exhibits a greater degree of lateral mixing $(P \simeq 1.0)$ than suggested by other workers for planar beaches. This would appear to result directly from the increased velocity gradients induced by the bar.

(6) Finally, it is likely that using planar beach equivalents for $P$ or $N$ in models for barred beaches will result in significant under-prediction of the appropriate eddy viscosity .

\section{ACKNOWLEDGEMENTS}

This study forms a part of a continuing research programme in Coastal Hydrodynamics and Sedimentation at Scarborough College supported by both capital (E39218, E6614) and operating grants (A7956) awarded to B.G. from the Natural Sciences and Engineering Research Council of Canada. A University of Toronto Open Fellowship, an Ontario Graduate Scholarship and a Post-doctoral Scholarship at Woods Hole Oceanographic Institution are acknowledged by D.J.S. Assistance with computer costs was given by both Scarborough College and the Department of Geography, University of Toronto. The Academic Workshop at Scarborough College assisted with instrument design and construction, while the Graphics and Photography Division of the College produced the illustrations. We gratefully acknowledge field and laboratory assistance from $M$. Rollingson, P. Christilaw and R. Sutherland, Scarborough College and R.G.D. Davidson-Arnott and D.C. Randall, Department of Geography, University of Guelph. We 
would like to thank the reviewers for their constructive criticism; however, the results and interpretations presented are the responsibility of the authors alone.

\section{REFERENCES}

Allender, J.H., Ditmars, J.D., Harrison, W. and Paddock, R.A., 1979. Comparison of model and observed nearshore circulation. Proc. 16th Int. Conf. Coastal Eng., pp. 810-827.

Allender, J.H. and Ditmars, J.D., 1981. Field measurements of longshore currents on a barred beach. Coastal Eng., 5: 295-309.

Basco, D.R., 1982. Surf Zone Currents, Vol. I. U.S. Army Corps of Engineers, Coastal Engineering Research Center, Misc. Rep. No. 82-7(I), Ft. Belvoir, VA, 243 pp.

Battjes, J.A., 1975. Modeling of turbulence in the surf zone. Symposium on Modeling Techniques, A.S.C.E., New York, N.Y., Vol. II, pp. 1050-1061.

Bowen, A.J., 1969. The generation of longshore currents on a plane beach. Mar. Res., 37: 206-213.

Ebersole, B.A. and Dalrymple, R.A., 1981. Numerical modelling of nearshore circulation. Proc. 17 th Int. Conf. Coastal Eng., Sydney, pp. 2710-2725.

Galvin, C.J. and Eagleson, P.S., 1965. Experimental study of longshore currents on a plane beach. TM-10, U.S. Army, Corps of Engineers, Coastal Engineering Research Center, Washington, D.C., 80 pp.

Grant, W.D. and Madsen, O.S., 1979. Combined wave and current interaction with a rough bottom. J. Geophys. Res., 84: 1797-1808.

Grant, W.D. and Madsen, O.S., 1982. Movable bed roughness in unsteady oscillatory flow. J. Geophys. Res., 87: 469-481.

Greenwood, B., 1982. Hydrodynamics and sedimentation in barred nearshores: a review of work by the Scarborough College Coastal Research Group. Proc. 3rd Workshop on Great Lakes Coastal Erosion and Sedimentation NWRI, Burlington, Ontario, pp. $45-48$.

Greenwood, B. and Davidson-Arnott, R.G.D., 1975. Marine bars and nearshore sedimentary processes, Kouchibouguac Bay, New Brunswick, Canada. In: J.R. Hails and A. Carr (Editors), Nearshore Sediment Dynamics and Sedimentation. Wiley, London, pp. 123-150.

Greenwood, B. and Sherman, D.J., 1983. Shore-parallel flows in a barred nearshore. Proc. 18th Int. Conf. Coastal Eng., Cape Town, South Africa, pp. 1677-1696.

Greenwood, B. and Sherman, D.J., 1984. Waves, currents, sediment flux and morphological response in a barred nearshore system. In: B. Greenwood and R.A. Davis, Jr. (Editors), Hydrodynamics and Sedimentation in Wave-dominated Coastal Environments. Mar. Geol., 60: 31-60.

Harris, T.F.W., Jordaan, J.M., McMurray, W.R., Verwey, C.J. and Anderson, F.P., 1962. Mixing in the surf zone. Int. J. Air Water Pollut., 7: 649-667.

Horikawa, K. and Isobe, M., 1981. Dynamic characteristics in the nearshore area. Proc. 17 th Int. Conf. Coastal Eng., Sydney, pp. 480-498.

Inman, D.L., Tait, R.J. and Nordstrom, C.E., 1971. Mixing in the surf zone. J. Geophys. Res., 76: 3493-3541.

Jonsson, I.G., 1980. A new approach to oscillatory rough turbulent boundary layers. Ocean Eng., 7: 109-152, 567-570.

Jonsson, I.G., Skovgaard, O. and Jacobsen, T.S., 1975. Computation of longshore currents. Proc. 14th Int. Conf. Coastal Eng., New York, N.Y., pp. 699-714.

Komar, P.D., 1975. Nearshore currents: Generation by obliquely incident waves and longshore variations in breaker height. In: J. Hails and A. Carr (Editors), Nearshore Sediment Dynamics and Sedimentation. Wiley, pp. 17-45.

Kraus, N.C. and Sasaki, T.O., 1979. Influence of wave angle and lateral mixing on the longshore current. Mar. Sci. Commun., 5: 91-126. 
Liu, P.L-F. and Dalrymple, R.A., 1978. Bottom frictional stresses and longshore currents due to waves with large angles of incidence. J. Mar. Res., 36: 357-375.

Longuet-Higgins, M.S., 1981. The unsolved problem of breaking waves. Proc. 17th Int. Conf. Coastal Eng., Sydney, pp. 1-28.

Longuet-Higgins, M.S., 1972. Recent progress in the study of longshore currents. In: R.E. Meyer (Editors), Waves on beaches and resulting sediment transport. Academic Press, New York, N.Y., pp. 203-248.

Longuet-Higgins, M.S., 1970a. Longshore currents generated by obliquely incident sea waves, 1. J. Geophys. Res., 75: 6778-6789.

Longuet-Higgins, M.S., 1970b. Longshore currents generated by obliquely incident sea waves, 2. J. Geophys. Res., 75: 6790-6801.

Longuet-Higgins, M.S. and Fenton, J.D., 1974. On the mass, momentum, energy and circulation of a solitary wave. II. Proc. R. Soc. London, Ser. A, 340: 471-493.

Longuet-Higgins, M.S. and Stewart, R.W., 1962. Radiation stress and mass transport in gravity waves. J. Fluid Mech., 13: 481-504.

Longuet-Higgins, M.S. and Stewart, R.W., 1963. A note on wave set-up. J. Mar. Res., 21: $4-10$.

Longuet-Higgins, M.S. and Stewart, R.W., 1964. Radiation stresses in water waves: A physical discussion. Deep Sea Res., 11: 529-562.

Madsen, O., Ostendorf, D.W. and Reyman, A.S., 1978. A longshore current model. Proc. Coastal Zone '78, ASCE, San Francisco, Calif., pp. 2332-2341.

Munk, W.H., 1949. The solitary wave theory and its application to surf problems. Ann. N.Y. Acad. Sci., $51: 376-424$.

Nikuradse, J., 1932. Gesetzmassigkeiten der turbulenten Stromung in glatten Rohren. Verein Deutsch. Ing., Forschungsh. 356.

Nikuradse, J., 1933. Stromungsgetze in rauhen Rohren. Verein Deutsch. Ing., Forschungsh. 361.

Ostendorf, D.W. and Madsen, O.S., 1979. An analysis of longshore currents and associated sediment transport in the surf zone. R.M. Parsons Laboratory for Water Resources and Hydrodynamics, Report No. MITSG 79-13, Cambridge, Mass., Massachusetts Institute of Technology, $169 \mathrm{pp}$.

Pawka, S.S., Inman, D.L., Lowe, R.L. and Holmes, L.C., 1976. Wave climate at Torrey Pines Beach, Technical Paper No. 76-5, U.S. Army, Corps of Engineers, Coastal Engineering Research Center, Washington, D.C.

Prandtl, L., 1952. Essentials of Fluid Dynamics. Hafner Publications, New York, N.Y.

Sherman, D.J., 1983. Longshore currents: a stress balance approach. Ph.D. Dissertation, University of Toronto, $193 \mathrm{pp}$. (unpubl.).

Sherman, D.J. and Greenwood, B., 1984. Boundary roughness and bedforms in the surf zone. In: B. Greenwood and R.A. Davis, Jr. (Editors), Hydrodynamics and Sedimentation in Wave-dominated Coastal Environments. Mar. Geol., 60: 199-218.

Sherman, D.J. and Greenwood, B., 1986. Determination of the angle of wave approach in shallow water. Journal of Waterway, Port, Coastal and Ocean Engineering, American Society of Civil Engineers, 112: 129-139.

Smith, J.D. and McLean, S.R., 1977. Spatially averaged flow over a wavey surface. J. Geophys. Res., 82: 1735-1746.

Sonu, C.J., 1972. Field observations of nearshore circulation and meandering currents. J. Geophys. Res., 77: 3232-3247.

Symonds, G. and Huntley, D.A., 1980. Waves and currents over nearshore bar systems. Proc. Can. Coastal Conf., 1980, National Research Council of Canada, Ottawa, pp. $64-78$.

Teleki, P.G., Schwartz, R.K. and Musialowski, F.R., 1976. Nearshore waves, currents and sediment transport. Abstr., Proc. 15th Int. Conf. Coastal Eng., Honolulu, Hawaii, pp. $569-572$.

Thornton, E.B., 1971. Variation of longshore current across the surf zone. Proc. 12th Int. Conf. Coastal Eng., Washington, D.C., pp. 291-308.

Thornton, E., 1978. Review of longshore current relationships and data base. Proc. Workshop on Coastal Sediment Transport, University of Delaware, pp. 41-57. 